\title{
Comparison of intranasal and oral desmopressin for nocturnal enuresis
}

\author{
A FJELLESTAD-PAULSEN, S WILLE, AND A S HARRIS
}

Department of Paediatrics, Malmö General Hospital, Malmö, Open Paediatric Clinic, Falkenberg, and Faculty of Pharmacy, Biomedical Centre, Uppsala, Sweden

SUMMARY A single blind dose response study of the effects of treatment with tablets containing $50-400 \mu \mathrm{g}$ of desmopressin was conducted in 15 children with primary nocturnal enuresis. A dose response effect was seen, with the 100,200 , and $400 \mu \mathrm{g}$ doses resulting in significantly more dry nights than when a placebo was used. The response after $200 \mu \mathrm{g}$ was significantly different from that after $100 \mu \mathrm{g}(\mathrm{p}<0.02)$ but not from that after $400 \mu \mathrm{g}$.

A randomised, double blind, double dummy, cross over study was then carried out in 30 children to compare the effects of a $20 \mu \mathrm{g}$ dose given through a nasal pipette, a $200 \mu \mathrm{g}$ tablet, and a placebo. The numbers of dry nights were significantly greater during both periods of treatment with desmopressin when compared with that using placebo, but there were no differences between the methods of taking the drug. After oral and nasal treatment $41 \%$ and $52 \%$, respectively, of the patients improved by more than $50 \%$. Nine children $(31 \%)$ remained completely dry after treatment.

Desmopressin is a potent, long acting antidiuretic polypeptide that has been shown to be an effective treatment of enuresis both in children and adults when given intranasally. ${ }^{1-4}$ An oral preparation of the drug has recently been developed, which is effective in the treatment of neurogenic diabetes insipidus. ${ }^{5-7}$ The intranasal and the oral routes for giving desmopressin were compared in 10 children with diabetes insipidus and found to give equivalent results. ${ }^{8}$ Encouraged by these findings, we sought to establish whether a tablet of desmopressin could be used to treat nocturnal enuresis. This study reports the results of a dose response trial of desmopressin given orally to 15 enuretics, followed by a double blind, double dummy, cross over, trial comparing oral, intranasal, and placebo preparations.

\section{Patients and methods}

Dose response study. Nine boys and six girls, aged from 6 to 14 (mean 8.7 , SD 2.9 years) with primary nocturnal enuresis were treated with oral desmopressin in a single blind dose ranging study that was preceded and followed by a week without any treatment. After one week of taking placebo tablets the children were given tablets containing 50,100, 200 , and $400 \mu \mathrm{g}$ desmopressin, in this sequence, for a week each. The number of dry nights each week was recorded, and the children were weighed every morning. Urine osmolality was estimated once a week from a urine sample taken at $5 \mathrm{am}$, and serum sodium concentrations were measured before and after treatment.

Comparative study. The second study comprised 20 boys and 10 girls, aged from 6 to 15 (mean 9.8, SD 2.5 years) with primary nocturnal enuresis. Each child had at least three wet nights a week during the period of observation. Half the children gave a family history of bed wetting, and $69 \%$ had tried one or more of the following treatments: enuresis alarm $(n=18)$, intranasal desmopressin $(n=7)$, tricyclic antidepressants $(\mathrm{n}=8)$, or anticholinergic drugs $(n=6)$. All treatments were stopped at least four weeks before the period of observation. Patients with urinary tract infections, faecal soiling, or neurological or urological abnormalities, were excluded.

The study was designed as a randomised, double blind, double dummy, cross over trial of $200 \mu \mathrm{g}$ desmopressin given orally, $20 \mu \mathrm{g}$ desmopressin given intranasally, and placebo treatment. The periods of treatment were preceded and followed by one week of observation. For six weeks patients were allo- 
cated each of the following regimens at fortnightly intervals: placebo tablet and placebo nasal pipette for the first two weeks, followed by two weeks each on either intranasal or oral desmopressin, according to the double dummy, cross over design. All drugs were taken at bed time, and there was no 'washout' period between the regimens as the cumulative effects have been shown to be small. ${ }^{2} 3$ Patients or parents recorded on a diary card the number of wet nights during each period. In addition, bed wetting was recorded using an enuresis score $(0=$ dry, $1=$ slightly wet, $2=$ very wet). Children were weighed each morning, and urine osmolality and serum sodium concentrations were determined at weekly intervals from a sample of urine taken at $5 \mathrm{am}$. Blood pressure and concentrations of albumin and creatinine in serum were measured regularly. Informed consent was obtained from all patients or parents, and the protocol was approved by the ethical committee of Malmö-Lund University.

Statistical methods. The results were expressed as mean (SEM). All data were tested for normality with the Wilk-Shapiro test. The paired Student's $t$ test was used to analyse normally distributed data, and non-parametric tests (paired Wilcoxon signed rank test and $\chi^{2}$ test) were used for the others.

\section{Results}

Dose response study. The number of dry nights each week rose with each increasing dose of desmopressin (Fig. 1). Significant differences between the placebo treatments were seen at doses of $100 \mu \mathrm{g}$ $(\mathrm{p}<0.05), 200 \mu \mathrm{g}(\mathrm{p}<0.05)$, and $400 \mu \mathrm{g}(\mathrm{p}<0.01)$. The $200 \mu \mathrm{g}$ dose produced a significant increase in the number of dry nights compared with the $100 \mu \mathrm{g}$ dose $(\mathrm{p}<0.02)$, but no difference was seen when the

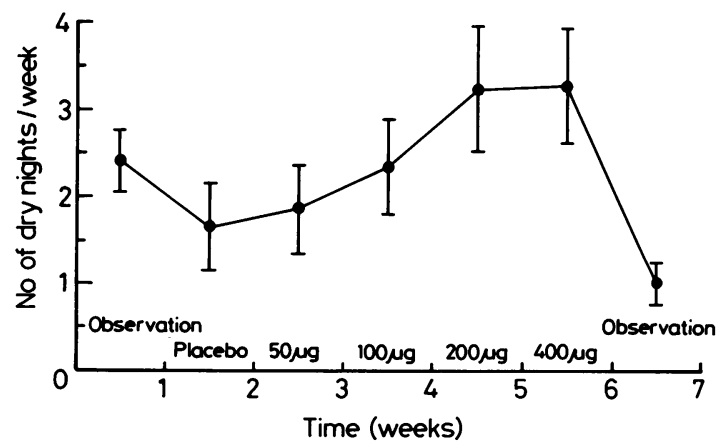

Fig. 1 The response to single increasing doses of desmopressin given orally to 15 enuretic children.
$200 \mu \mathrm{g}$ and $400 \mu \mathrm{g}$ doses were compared. Urine osmolality in specimens taken at 5 am increased weekly with the $400 \mu \mathrm{g}$ dose, 1000 (45) $\mathrm{mOsm} / \mathrm{kg}$ being significantly different from the measurement recorded when the placebo was being taken, of 851 (47) $\mathrm{mOsm} / \mathrm{kg}, \quad(\mathrm{p}<0 \cdot 05)$. No side effects were recorded. No significant changes in bodyweight were seen except when the $400 \mu \mathrm{g}$ dose was being taken; a significant increase over the preceding week occurred $(p<0 \cdot 01)$. No significant differences between sodium concentrations in serum before and after treatment were found. We concluded that a dose of $200 \mu \mathrm{g}$ desmopressin taken orally was suitable for further controlled studies.

Comparative study. Thirty patients entered the double blind study to compare the effects of desmopressin given either orally or intranasally. One boy withdrew after the study had started. During the observation period the mean number of dry nights a week was $2 \cdot 2(0 \cdot 2)$, and this did not rise significantly when the placebo was being taken. During both periods of treatment with desmopressin, the mean number of dry nights doubled (Fig. 2) when compared with placebo $(p<0 \cdot 001)$, but there was no difference between the methods of giving the drug. Several patients relapsed when the treatment had finished, but nine children $(31 \%)$ remained completely dry.

In an attempt to grade the response to desmopressin the percentage improvement with both methods was compared with the level before treatment (Fig. 3). Nine patients taking tablets improved by $75-100 \%$, and two of them were totally dry, while five and one patient, respectively, responded similarly to the drug given nasally. Seven patients did not respond to tablets, and only two did not respond to nasal treatment.

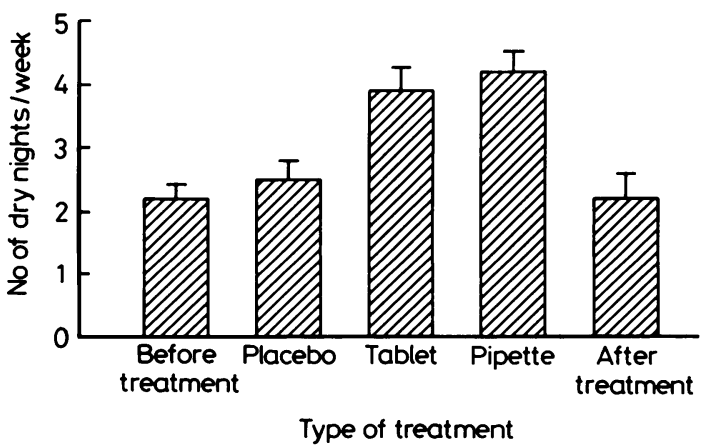

Fig. 2 No of dry nights a week after placebo, intranasal $(20 \mu \mathrm{g})$ and oral $(200 \mu \mathrm{g})$ desmopressin in 29 enuretic children. 


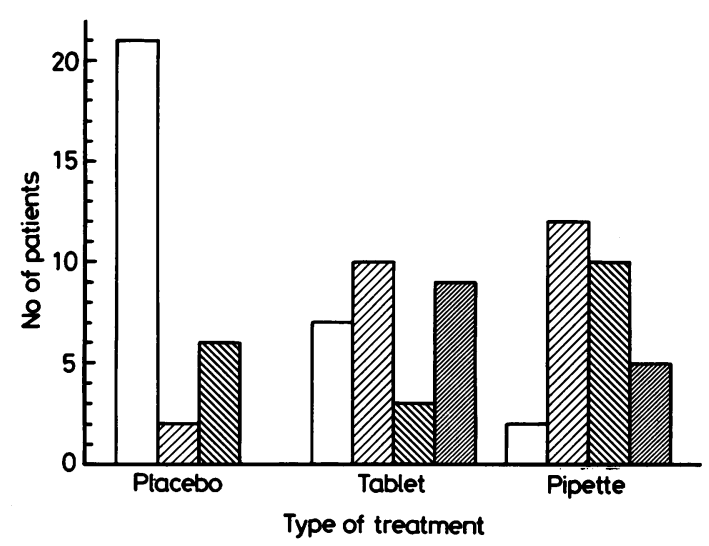

Fig. 3 Graded response to placebo, intranasal, and oral desmopressin expressed as a percentage of the pretreatment response in 29 enuretic children. $\bar{\square} 0-24 \% ; \square 25-49 \%$; 50-74\%; $75-100 \%$ improvement.

Table Response to treatment with desmopressin and urine osmolality measured in specimen taken at 5.00 am

\begin{tabular}{lllll}
\hline $\begin{array}{l}\text { Urine osmolality } \\
\text { (mOsm/kg) }\end{array}$ & $\begin{array}{l}\text { No } \\
\text { remaining } \\
\text { dry }\end{array}$ & $\begin{array}{l}\text { No who } \\
\text { greatly } \\
\text { improved }\end{array}$ & $\begin{array}{l}\text { No who } \\
\text { slightly } \\
\text { improved }\end{array}$ & $\begin{array}{l}\text { No with } \\
\text { no } \\
\text { improvement }\end{array}$ \\
\hline$>1000$ & 7 & 9 & 4 & 2 \\
$>800-1000$ & 0 & 4 & 0 & 1 \\
$>600-800$ & 0 & 0 & 1 & 0 \\
$<600$ & 0 & 0 & 0 & 1 \\
\hline Total & 7 & 13 & 5 & 4 \\
\hline
\end{tabular}

Greatly improved=only one or two wet nights a week; slightly improved=one or more dry nights a week compared with placebo; no improvement $=$ no change from placebo.

Measurements of urine osmolality were higher during intranasal and oral treatment with desmopressin, but not significantly different from the measurements before treatment, or when the placebo was being taken. When patients were graded by response and stratified by measurements of urine osmolality, however, there was a clear and significant relation between the clinical response and the osmotic concentration of morning urine (Table). The best results were obtained in patients who had osmolality measurements of over 1000 $\mathrm{mOsm} / \mathrm{kg}$. Three patients had decreased serum concentrations of sodium (to $125-130 \mathrm{mmol} / \mathrm{l}$ ) during treatment, but these returned to normal when desmopressin was stopped. The mean values were not significantly different throughout the study, and body weight was steady during the eight weeks. One patient had a low concentration of sodium in the serum before treatment and when the placebo was being taken, which may indicate polydipsia. There were no changes throughout the trial in concentrations of albumin or creatinine in serum, or in blood pressure readings.

No significant adverse effects were registered, but some patients complained of occasional nasal discomfort $(n=2)$ and epistaxis $(n=3)$; no difference was found between placebo and desmopressin treatment.

\section{Discussion}

The results of this study confirm the efficacy of desmopressin in the treatment of nocturnal enuresis and show that a single oral dose of $200 \mu \mathrm{g}$ was as effective as a $20 \mu \mathrm{g}$ dose given intranasally. Until recently the value of giving polypeptides orally was underestimated because it was thought that they were hydrolysed before reaching the absorption sites in the gastrointestinal tract. During the past two decades, however, oral absorption of dipeptides and tri-peptides has been shown. ${ }^{9}{ }^{10}$ Furthermore, studies performed in rats, dogs, and man have shown that vasopressin, its analogues, and desmopressin in particular may all be absorbed when taken orally. ${ }^{11}$ More recently, several studies have reported that long term treatment with desmopressin taken orally is both safe and effective in adults ${ }^{5} 12$ and children ${ }^{6} 7$ with diabetes insipidus. Usually doses 10 to 20 times larger are needed for oral treatment, and patients with diabetes insipidus respond better taking three doses a day rather than two.

Several studies have shown significantly better results when desmopressin given intranasally in different doses was compared with placebo. ${ }^{1-3} 1314$ The drug works quickly, but relapses are common after treatment has finished. In our study nine patients $(31 \%)$ remained dry after treatment, the others relapsed immediately. The mean number of dry nights a week after treatment in those that relapsed was $1.2(0.3)$, which was noticeably worse than the mean during the observation week of 1.9 $(0.3)$, or that observed when they were taking the placebo of $2 \cdot 3(0 \cdot 3)(p<0 \cdot 05)$. This shows that there is a large percentage of patients who respond well to treatment, and even an observation period or waiting list for treatment will produce an improvement. Once treatment is over, however, most relapse immediately, and probably are closer to a real enuretic state than during the period before treatment.

The effect seems to be dose related, but in general the $20 \mu \mathrm{g}$ dose given intranasally is used independently of age and body weight. In a recent study in 10 children with diabetes insipidus $10 \mu \mathrm{g}$ given intranasally was equivalent to $200 \mu \mathrm{g}$ given orally, and 20 
$\mu \mathrm{g}$ given intranasally was equivalent to $400 \mu \mathrm{g}$ given orally. ${ }^{8}$ We decided to compare the $20 \mu$ g intranasal dose with the $200 \mu \mathrm{g}$ oral dose, which we found in a pilot study to be as effective as a $400 \mu \mathrm{g}$ dose, but with less effect on serum electrolytes and body weight.

The mechanism of action of desmopressin in nocturnal enuresis has been widely discussed. Birkasova ${ }^{1}$ postulated that it worked through its antidiuretic effect. Wille ${ }^{15}$ and, more recently, Dimson $^{16}$ found significant positive correlations between morning urine osmolality and clinical response during treatment with desmopressin given intranasally. Our results confirm these findings. Furthermore, these results suggest that the efficacy of desmopressin is related to its ability to raise overnight urinary osmotic concentration by increasing water reabsorption, and so reducing the diuresis and the volume of urine entering the bladder.

One of the many theories about the pathogenesis of enuresis is that enuretics may lack a nocturnal rise in secretion of endogenous vasopressin. George et $a l^{17}$ were the first to describe a diurnal rhythm of vasopressin in normal adults which reached appreciably higher concentrations at night. In two uncontrolled studies Nørgaard et al ${ }^{18}$ and Puri ${ }^{19}$ showed that vasopressin secretion in enuretic children failed to increase at night; one of the reasons for involuntary nocturnal micturition, therefore, may be nocturnal polyuria, which causes urine production to exceed bladder capacity. If this finding is substantiated by further controlled studies desmopressin may be a useful substitute for nocturnal vasopressin for patients with enuresis compounded by nocturnal polyuria.

Desmopressin given either nasally or orally can be used safely and effectively for most enuretic children; it is especially useful for those spending nights away from home. Relapses after stopping treatment are common, however, but most patients considered desmopressin to be more effective than previous treatment, and the children were willing to continue treatment by either route.

We thank the nursing staff of the two paediatric departments, and Ferring AB, Malmö, Sweden, for the desmopressin tablets and pipettes.

\section{References}

' Birkasova M, Birkas O, Flynn MJ. Cort JH. Desmopressin in the management of nocturnal enuresis in children: a doubleblind study. Pediatrics 1978;62:970-4.

2 Dimson SB. Desmopressin as a treatment for enuresis. Lancet 1977:i: 1260.

3 Tuvemo T. DDAVP in childhood nocturnal enuresis. Acta Paediatr Scand 1978;67:753-5.

+ Ramsden PD, Hindmarsh JR, Price DA, Yeates WK, Bowditch JDP. DDAVP for adult enuresis-a preliminary report. $\mathrm{Br}$ J Urol 1982;54:256-8.

${ }^{5}$ Hammer M, Vilhardt H. Peroral treatment of diabetes insipidus with a polypeptide hormone analog. Desmopressin. J Pharmacol Exp Ther 1985;234:754-60.

${ }^{6}$ Fjellestad A. Czernichow P. Central diabetes insipidus in children. V. Oral treatment with a vasopressin hormone analogue (DDAVP). Acta Paediatr Scand 1986;75:605-10.

7 Westgren U, Wittström C, Harris AS. Oral desmopressin in central diabetes insipidus. Arch Dis Child 1986;61:247-50.

${ }^{8}$ Fjellestad A, Tubiana N, Harris AS, Czernichow P. Central diabetes insipidus in children: Antidiuretic effect and pharmacokinetics of intranasal and peroral DDAVP. Acta Endocrinol (in press).

9 Matthews DM, Lis ML, Cheng B, Crampton RF. Observations on the intestinal absorption of some oligopeptides of methionine and glycine in the rat. Clin Sci 1969;37:751-64.

10 Adibi S, Morse EL. Intestinal transport of dipeptides in man: relative importance of hydrolysis and intact absorption. J Clin Invest 1971;50:2266-75

11 Vilhardt H, Hammer M, Bie P. Peroral administration of antidiuretic peptides to conscious dogs, normal humans and patients with diabetes insipidus. Frontiers of Hormone Research 1985;13:314-20.

12 Cunnah D, Ross G, Besser GM. Management of cranial diabetes insipidus with oral desmopressin (DDAVP). Clin Endocrinol 1986:24:253-7.

13 Aladjem M, Wohl R, Boichis H, Orda S, Lotan D, Freedman S. Desmopressin in nocturnal enuresis. Arch Dis Child 1982:57:137-40.

14 Terho P, Kekomäki M. Management of nocturnal enuresis with a vasopressin analogue. J Urol 1984;131:925-7.

is Wille S. Comparison of desmopressin and enuresis alarm for nocturnal enuresis. Arch Dis Child 1986;61:30-3.

16 Dimson SB. DDAVP and urine osmolality in refractory enuresis. Arch Dis Child 1986;61:1104-7.

17 George CPL, Messerli FH, Genest J, et al. Diurnal variation of plasma vasopressin in man. $J$ Clin Endocrinol Metab 1975;41:332-8.

${ }^{18}$ Nørgaard JP, Pedersen EB, Djurhuus JC. Diurnal anti-diuretichormone levels in enuretics. $J$ Urol 1985;134:1029-31.

${ }_{19}$ Puri VN. Urinary levels of antidiuretic hormone in nocturnal enuresis. India Pediatr 1980;17:675-6.

Correspondence to $\operatorname{Dr}$ S Wille, Paediatric Clinic, S-311 01 Falkenberg, Sweden.

Received 25 February 1987 